\title{
Unjani Clinics: meeting the need for scale through social franchising
}

\author{
Anna Szerb $^{1}\left[\right.$ ] Ilze Kivleniece $^{1} \cdot$ Vikas Aggarwal $^{1}$ \\ Received: 22 July 2021 / Accepted: 27 October 2021 / Published online: 8 November 2021 \\ (C) The Author(s), under exclusive licence to Organizational Design Community 2021
}

\begin{abstract}
In this contribution to the Organization Zoo series, we discuss an organization with a unique organization design that allows for a scalable and financially sustainable approach to social impact. Unjani Clinics is a network of nurse-led clinics in South Africa, where the nonprofit (head office) organization oversees the operations of more than ninety for-profit independent primary healthcare clinics. Combining for-profit and nonprofit entities in a social franchise structure represents a unique bundle of organization design choices that together enable the organization to effectively pursue its mission. By combining entrepreneurial incentives for nurses, such as ownership rights over their clinics, with social impact-driven controls, Unjani cultivates an otherwise untapped resource-i.e., professional nurses' entrepreneurial ambitions- to deliver on its social mission. This novel combination of entrepreneurial autonomy with formal hierarchical as well as informal controls to safeguard the social mission allows Unjani to address the tension between social and financial value creation, which often prevents social enterprises from scaling successfully.
\end{abstract}

Keywords Social franchising $\cdot$ Scale $\cdot$ Hybrid organizations $\cdot$ Autonomy

\section{Introduction}

Unjani Clinics is a network of nurse-led clinics that aims to "perfect a sustainable clinic model for providing primary healthcare" in South Africa. ${ }^{1}$ The organization is structured as a social franchise, where Unjani nurses, the "franchisees", are both providers of affordable healthcare services for those unable to access private health insurance, as well as entrepreneurs, who lead their respective primary healthcare clinics, taking on full responsibility for all expenses and entitled to all revenues. The network of clinics is headed by a non-profit company (the "NPC") that acts as a franchisor, overseeing the entire network, as well as determining the list and pricing of services delivered in each clinic. These services are standardized across the entire network. Unjani Clinics thus represents a model that aims for a sustainable provision of affordable, high-quality primary healthcare care

Anna Szerb

anna.szerb@insead.edu

Ilze Kivleniece

ilze.kivleniece@insead.edu

Vikas Aggarwal

vikas.aggarwal@insead.edu

1 INSEAD, Blvd de Constance, 77300 Fontainebleau, France services, without reliance on the public healthcare system, while simultaneously empowering black professional nurses to become successful (social) entrepreneurs. As such, the unique "social franchise" model of Unjani Clinics enables the organization to pursue large-scale social impact in a novel way. A closer look at the organization design features of Unjani Clinics, we argue, may offer fruitful insights as to how organizations driven by a social mission can meet the need for scale.

\section{What is Unjani Clinics?}

The concept of Unjani Clinics was originally developed by Dr. Iain Barton, the Managing Director of a consumer healthcare supply chain services company from 2013 (Imperial Health Services, IHS). Dr. Barton observed that in South Africa, the two-tiered healthcare system leaves around $84 \%$ of the population reliant on self-insurance or on the overburdened public healthcare system in order to meet their medical needs. As a former general practitioner, he also noted that the existing healthcare system relied heavily on highly trained and expensive physicians to deliver, for most part, relatively simple, routine primary care services. From this

\footnotetext{
1 https://www.unjaniclinic.co.za/home/ accessed on 06/01/2021.
} 
observation, the idea was born to pilot the use of converted shipping containers as facilities for primary healthcare clinics, lead by professional nurses who would perform the majority of largely routine medical tasks involved in primary healthcare provision (as opposed to more costly and scarce physician resources), while also taking on full financial and operational responsibility for running the clinics, and eventually assuming ownership of the associated asset (i.e., the physical clinic facility). IHS funded the infrastructure and the set-up costs of the first six clinics and after the concept was proven, in 2014 an independent non-profit organization, Unjani Clinics NPC, was established, headed by CEO Lynda Toussaint. This organization builds on its own resources, as well as resources provided by a diverse set of external partners, to fund further expansion of the network. The NPC currently oversees a network of over 90 clinics.

The first six Unjani clinics served as pilots, and the organizational and operational model was adjusted after 2014 to improve the infrastructure and to include a community survey and business proposal requirements as part of the nurse selection process. The organization completed a milestone in October 2020, reaching over 1.5 million consultations since its establishment. The organization's goal is to open 1,000 clinics by 2030 (Stern et al. 2020). While there is still a reliance on external donor funding to open new clinics, the organization is piloting a "blended financing model" for nurses, which introduces a loan component to the inheritance process of the clinics by nurses, supporting the NPC in achieving its goal of no reliance on donor funding by the opening of the $100^{\text {th }}$ clinic. During the coronavirus pandemic in 2020, Unjani Clinics continued its commitment toward improving the health of its communities by participating in the South African pilot deployment of five modular Covid-19 testing units in densely populated, lowincome urban areas in order to expand Covid-19 screening and treatment opportunities. ${ }^{2}$

\section{A unique organizational design for a "Social Franchise"}

The franchise structure of Unjani Clinics allows a non-profit (head) organization, the NPC, to oversee the operations of its network of for-profit, independently run primary healthcare clinics. The NPC identifies new geographical areas for clinic establishment, selects nurse-entrepreneurs, and signs a five-year "Enterprise Development Agreement" with them, in which nurses agree to adhere to both the financial and

\footnotetext{
2 https://www.engineeringnews.co.za/article/ifc-backs-imperial-rollo ut-of-modular-covid-19-screening-treatment-units-2020-09-23/rep_ id:4136 accessed on 06/01/2021.
}

clinical requirements of running an Unjani clinic, such as ongoing financial reporting, regulatory and procedural compliance, and financial targets. The NPC provides the initial infrastructure, medical equipment, 24 months of operational donations, and continued mentoring, as well as financial training. Once nurses sign off on receipt of the clinic after completing the essential training at the start, they are responsible for all operating expenses, and they retain rights to all revenue from consultation fees, as well as from the sale of over-the-counter products and nutritional supplements. The nurses pay an upfront fee to the Unjani head organization, NPC (to have, as the head organization describes it, "skin in the game"), and are also expected to pay a "network fee" from the first year onwards. This network fee increases exponentially by year 5 , when the clinics are expected to become profitable, or at least to break even. After five years, nurses can choose to remain in or depart from the Unjani Clinics (branded) network. If they depart, they can continue to operate independently. The terms of the agreement are formulated so as to have nurses become entrepreneurs and owners of a sustainable micro-organization (i.e. their own clinic) during the 5-year period as long as they adhere to their contractual obligations.

The novelty of organization design of Unjani Clinics lies in the combination of a non-profit entity within a typically for-profit franchise structure, thus effectively coordinating the operations of for-profit entities towards a common, socially-driven organizational goal. By combining the features and operating logics from multiple organizational forms, such as for-profit and charity enterprises, Unjani thus represents what has been termed a "hybrid organization" (Battilana and Lee 2014). Yet, the way Unjani Clinics combines social and commercial incentives in an entrepreneurial model makes it a unique form of a "social franchise," a relatively less well-known form of hybrid organization. While the social franchising concept has been discussed in prior literature (Asemota and Chahine 2017; Cumberland and Litalien 2018; Tracey and Jarvis 2007), Unjani Clinics employs a bundle of novel organization design features that, taken together, comprise its unique organizational form. These design features combine entrepreneurial autonomy with hierarchical safeguards to reduce the natural tension between the franchisor and franchisee, "incubate" organizational members, and contribute toward building a transparent organizational culture to achieve social mission-driven growth.

\section{Balancing authority with autonomy to safeguard the social mission}

As prior literature suggests, hybrid organizations may face important tensions arising from the multiplicity of organizational objectives and stakeholder demands (Battilana et al. 
2015; Battilana and Dorado 2010; Battilana and Lee 2014). One of these tensions manifests in the area of organization design, as hybrid organizations address a tradeoff between enforcing authority to safeguard the social mission and providing sufficient autonomy for members to retain incentives to contribute their efforts towards both the financial and social objectives of the organization. This tension is especially acute if members' preferences over how the organizational mission should be achieved is not perfectly aligned with how the organization achieves its dual goals. Interestingly, the unique model of Unjani Clinics illustrates an organization design that may be able to address such tension. The head organization, the NPC, could have selected managers or classic for-profit entrepreneurs as franchisees to run the clinics, including the selection of professional nurses with a clearly delimited autonomy within the (social) franchise structure. Instead, the current structure arguably permits the head organization to better balance local autonomy in execution with a central authority that can safeguard the organization's overall social mission. Moreover, in terms of its social mission, given the unique design of the organization, Unjani, with its network of franchisees, creates positive social impact not just in terms of increasing access to primary healthcare in South Africa, but also by empowering black women professional nurses.

\section{Incubating "nursepreneurs"}

According to the CEO of Unjani Clinics, the (centrally run) selection process of the nurses is one of the key contributors to the successful growth of the Unjani network, and-from a more theoretical perspective - represents another key pillar of organization design features that sets the organization apart. To be selected, nurses have to meet certain pre-defined minimum eligibility criteria, including professional nurse qualifications and work experience. Furthermore, only black female professional nurses are considered, given the empowerement-related mission of Unjani Clinics. If a nurse meets the eligibility criteria, she is required to submit a business plan to the Unjani NPC within 30 days of the initial application. This plan includes, among other elements, securing a suitable site and a 5-year lease with the owner of the land for her clinic; a community survey the nurse is expected to conduct to assess the health needs of the local community; and her general business and financial plan for the clinic. Given that most professional nurses have not had any business training before applying to Unjani Clinics, this part of the selection process aims to gauge nurses' problem-solving capabilities, their resourcefulness in terms of conducting research and writing up a business plan, and their effectiveness in enaging with local communities. Nurses selected by the Unjani NPC Network General Manager are invited for an interview with the CEO of the head organization where they are required to present their business plan and pass a clinical questionnaire to assess their professional skills. ${ }^{3}$ Nurses selected to join the network then participate in a essential business training, sign a formal agreement with the NPC, pay their first network fee, and oversee the construction of their clinic before it starts to operate.

The first five years for each new Unjani Clinics' nurse defines the period during which she is expected to evolve from a professional nurse to a social entrepreneur (or a "nursepreneur") who is able to run a for-profit clinic successfully while complying with the financial and professional requirements of Unjani Clinics NPC. Beyond the daily operational and financial management of their clinics (within the requirements and performance indicators defined by the NPC), a key area of autonomy for the nurses lies in recruiting and growing their patient population, which involves ongoing marketing activities in the local community to reach patients who are able to pay a small fee for healthcare services but cannot afford private care. In terms of compliance, services offered locally are to a large extent standardized across the Unjani Clinics "franchise" network, and pricing is flat-rate in order to provide consistency across clinics and to ensure that nurses do not deviate from their focus on access to care rather than individual clinic profitability. Furthermore, some services are priced so that they support cross-subsidization with other more expensive services. Regular financial audits ensure financial transparency between the clinics and the NPC, and also ensure that nurses deliver high-quality, affordable primary care services to patients. Serious breaches of the agreement signed between the nurses and the NPC can result in the replacement of the nurse, and thus no eventual ownership of the clinic at the end of the five-year period.

Hybrid organizations often struggle with attracting and retaining crucial resources, especially human capital, given that engaging individuals with both a commercial and social "logic" can cause identity schisms within the organization (Battilana et al. 2015; Battilana and Dorado 2010). As we have observed, Unjani Clinics leverages its organizational design to "incubate" organizational members ("nursepreneurs") with the value alignment and commercial capabilities needed for continued growth of the network. This incubation process is enabled by its organization design (i.e., the franchise structure), but its success relies as well on a selection process that assesses professional nurse qualifications as well as business acumen, and other organizational culture-related practices that sustain nursepreneurs' motivation toward the social mission of the organization. Furthermore,

\footnotetext{
${ }^{3}$ Approximately 1 out of 5 applications make it to the interview phase and about 1 out of 3 interviewed nurses are selected to join the network.
} 
the organization also leverages dynamic resource transfer to support the scaling process, as it transfers ownership of the clinics from the NPC to the nurses once they have proven their ability to run the clinics in a financially sustainable manner and their willingness to adhere to the social mission of the organization.

\section{Building organizational culture for social mission-driven growth}

Growth poses a particular challenges for social enteprises as they may experience increasing pressure to deviate from the social mission and to move toward greater profitability as they grow (Ebrahim et al. 2014). The accomplishment of Unjani Clinics' mission largely stems from its ability to grow and increase its breadth of impact by increasing the number of clinics in the network, and doing so in a sustained manner while adhering to its overall mission. Unjani Clinics nurses, once they inherit their clinics after five years, for instance, are confronted with the choice of running their clinics independently and potentially focusing on services with the highest margins in order to increase their profitability (versus staying in the Unjani Clinics network and continuing to prioritize access to care over profitability). From the perspective of sustainable scaling, it is crucial that nurses who are willing to comply with the terms of the Unjani agreement stay within the network after five years, having acquired the skills to run their clinics profitably while adhering to the overall mission of the organization. Interestingly, over the course of the organization's history as the network has grown to include over 90 clinics, seven nurses have exited after completion of their 5 year agreement with the NPC, ${ }^{4}$ and four clinics have stopped operating.

There is evidence that having a common organizational identity for a hybrid organization is critical in avoiding a "mission-drift", an issue that is particularly salient in an organization's growth phase (Battilana and Dorado 2010; Ebrahim et al. 2014). Doing so, however, is notoriously difficult against the backdrop of multiple organizational goals. Through our field research at Unjani Clinics, we can better understand how distinct organizational culture enforces the organization design choices that permit Unjani Clinics to overcome tensions resulting from its hybrid nature. The NPC strives for close and transparent relationships with nurses to foster an open, almost familial culture in which nurses are supported in their path toward becoming successful entrepreneurs who endorse the social objectives of the organization. Nurses are encouraged to have frequent and informal

\footnotetext{
${ }^{4}$ In the (seven) areas covered by the nurses who exited the network, two new Unjani clinics were opened that now compete with those clinics outside the network.
}

contact with the CEO and the Network General Manager of head organization to raise any questions or concerns they have about their obligations towards the NPC, even if these are personal matters. Nurses are also given the opportunity through regular nurse conferences to provide their feedback on and thereby shape informally how the organization achieves its overall mission, for instance, in terms of the appropriateness of price controls. The close informal ties to the CEO and the Network General Manager, as well as the strong set of lateral ties among nurses, arguably, offer "nursepreneurs" a role model and supportive peers which enable them to stay motivated toward the organization's social mission.

\section{What can other socially driven organizations learn from Unjani Clinics in terms of scaling?}

The ability of a hybrid organizations to address societal challenges and have impact ultimately rests on these organizations being able to ensure ongoing, sustained growth (Dees and Anderson 2004) while remaining aligned in choices around organization design, structure and culture - a growth process known as organizational "scaling" (Desantola and Gulati 2017). We argue that Unjani Clinics demonstrates how scaling may be achieved and tensions common to hybrid organizations may be addressed in a novel way, via a unique social franchise model with organizational design features that set it apart from classical for-profit or nonprofit structures. From an organization design perspective, Unjani Clinics combines authority and autonomy in a way that allows "nursepreneurs" to have autonomy in operating their clinics, while the the head organization (NPC) is able to safeguard the social mission.

Can this unique combination of autonomy and authority within Unjani Clinics potentially provide valuable insights for the scaling-up of other hybrid organizations? We argue that the unique structure of the organization allows Unjani Clinics to effectively "incubate" its own social entrepreneurs and grow, while complying with the social mission of the organization. However, we also acknowledge that "layering" of different identities for the same organizational members (here, the "nursepreneurs") may not be replicable in all contexts. Furthermore, in terms of organizational culture, the informal organizational culture of Unjani is greatly supported by a highly welcoming and warm local culture in South Africa, and, exploring whether hybrid organizations in differing social and institutional contexts can scale in a similar manner may be a potentially fruitful avenue for future research. 
Acknowledgements The authors thank Lynda Toussaint and Sue Hoosain for their helpful input into this paper, as well as the editor and two anonymous reviewers for constructive comments.

Authors' contribution AS was responsible for the data collection, drafting and revising the manuscript. IK and VA contributed to all sections by revising and editing the manuscript. All authors read and approved the final manuscript.

Funding The authors gratefully acknowledge funding from the The Kurt Björklund MBA'96J Research Fund.

Availability of data and materials Not applicable.

\section{Declarations}

Competing interests The authors declare that they have no competing interests.

\section{References}

Asemota J, Chahine T (2017) Social franchising as an option for scale. Voluntas 28(6):2734-2762

Battilana J, Dorado S (2010) Building sustainable hybrid organizations: the case of commercial microfinance organizations. Acad Manag J 53(6):1419-1440
Battilana J, Lee M (2014) Advancing research on hybrid organizinginsights from the study of social enterprises. Acad Manag Ann 8(1):397-441

Battilana J, Sengul M, Pache AC, Model J (2015) Harnessing productive tensions in hybrid organizations: the case of work integration social enterprises. Acad Manag J 58(6):1658-1685

Cumberland DM, Litalien BC (2018) Social franchising: a systematic review. J Mark Channels 25(3):137-156

Dees JG, Anderson BB, Wei-Skillern J (2004) Scaling social impact. Stanford Soc Innov Rev 1:24-32

Desantola A, Gulati R (2017) Scaling: organizing and growth in entrepreneurial ventures. Acad Manag Ann 11(2):640-668

Ebrahim A, Battilana J, Mair J (2014) The governance of social enterprises: mission drift and accountability challenges in hybrid organizations. Res Org Behav 34:81-100

Stern I, Lee M, Chick SE, Aggarwal R (2020) Sustaining the mission: strategic options to scale Unjani Clinics NPC by 2030. INSEAD Ref 6445

Tracey P, Jarvis O (2007) Toward a theory of social venture. Entrep Theory Pract 31(5):667-685

Publisher's Note Springer Nature remains neutral with regard to jurisdictional claims in published maps and institutional affiliations. 